\title{
As FlORES DO MAL: \\ SINTOMA E SABER ANTI-MODERNOS
}

(BUCK-MORSS, Susan. "Hegel and Haiti". Em Critical Inquiry, Summer 2000, v. $26 \mathrm{n}^{\circ} 4$.)

(Cf. PICHOIS, Claude e Launay, Claude. "La modernité de Baudelaire". Em Sprachkunst. Beitrage zur Literaturwissenchaft.,vol. 15, no 2. Viena: 1984:197211.)

\section{Raúl Antelo}

Em Hegel and Haiti, Susan Buck-Morss defende uma idéia, a primeira vista, paradoxal: é nas margens que melhor se realiza a modernidade e, via de regra, a concepção iluminista que dela elaborou-se muitas vezes seqüestra e se apropria dessa compreeensão, para a qual urge fornecer, entretanto, uma nova genealogia..$^{*}$ Assim sendo, avaliar, hoje e aqui, As Flores do mal, obriga-nos a um percurso que pode parecer inusitado, mas que, certamente, só revela a nossa amnésia com relação ao caráter dual do conceito de modernidade.

Para tanto, permitam-me lembrar que, antes mesmo de sua Viagem a Havana, cuja primeira edição, em Paris, é de 1844, outra mulher, a condessa de Merlin, defendia uma idéia não menos paradoxal do que a de Buck-Morss: engajava-se a condessa pelo fim do comércio escravocrata, embora não pelo abolicionismo, com o argumento de que os negros cubanos dificilmente gostariam de alterar sua condição já que, dados à preguiça, encontravam, espontaneamente, todo tipo de excesso numa natureza que satisfazia "avec luxe à tous leurs désirs", e num solo, aliás, que os embriagava "avec des aromates exquis". ${ }^{2}$ Sem temer ser mal interpretada como poli-

${ }^{1} \mathrm{O}$ texto foi traduzido, parcialmente, ao espanhol pela revista Casa (Havana, Casa de las Américas) e, integralmente, como Hegel y Haití pela editora Norma (Buenos Aires, 2004).

2 "Supposons que les Anglais parviennent à obtenir sans secousse, sans trouble, l'émancipation des esclaves dans nos colonies; quelle sera chez nous l'existence de plus de sept cent mille nègres en face de trois cent mille blancs? Leur premier sentiment, leur premier besoin, quel sera-t-il? Ne rien faire. Je l'ai dit, un travail régulier leur est insupportable; la force a seule pu les y soumettre. Les colonies anglaises, après avoir répandu plus de 25 millions de francs, n'ont obtenu d'autre résultat que la ruine de l'agriculture et la transformation de l'ancien esclavage en un état d'oisiveté et de vagabondage plus malheureux et plus immoral que la servitude. N'avons nous pas encore sous les yeux le triste résultat de la révolution de Saint-Domingue, île jadis riche, florissante, splendide, aujourd'hui pauvre, inculte, délaissée, et produisant à peine de quoi nourrir ses oisifs habitants, toujours ivres de vin et de fumée de tabac? La paresse a d'autant plus d'empire sur les nègres, qu'elle n'est pas combattue par le besoin. A Cuba, la nature suffit avec luxe à tous leurs désirs; le sol offre sans culture et en profusion des racines colossales qu'on 
ticamente incorreta, a condessa queria, pois, definir o que se deveria entender, de fato, como liberté, sobretudo sob o ponto de vista de uma mulher e, para mais dados, mestiça. ${ }^{3}$

Após a minuciosa análise da escravidão na Louisiana, publicada também pela Revue des Deux Mondes, em 1855, o geógrafo francês Elisée Reclus estampa, na mesma revista, porém, em 1862, uma análise equivalente sobre "Le Brésil et la colonisation", apoiada, dessa vez, no livro de Avé Lallement e na obra de Spix e Martius." Pouco depois, em outra colaboração para a mesma revista, abordando o problema do sentimento da natureza nas sociedades modernas, magistralmente captado, aliás, por Humboldt, em seus Quadros da natureza, dedicados a todos aqueles que "par amour de la liberté, ont pu s'arracher aux vagues tempétueuses de la vie", o próprio Reclus argumenta que o sentimento ecológico se desenvolve e expande conforme aumenta "la multitude des hommes exilés des campagnes", dado o crescimento incomparável das grandes metrópoles, com seu inevitável corolário de deslocamentos em massa e enormes despovoamentos. ${ }^{*}$ Em mais uma obra, inexistente em francês, mas provavelmente construída a partir de fragmentos de sua magna opus prévia, a Nouvelle géographie universelle. La terre et les hommes (1876-94), epítome esse editado, sem data, em

assaisonne avec des aromates exquis, sans autre peine que celle de se baisser pour les cueillir. Une demeure? ils n'en ont pas besoin sous une atmosphère toujours brûlante, ou les nuits sont encore plus belles que les jours. Quatre pieux, quelques feuilles de palmier, voilà tout ce qu'il leur faut pour se reposer, et la voûte du ciel pour s'abriter. Quant aux vêtemens, la chaleur les leur rend inutiles, souvent insupportables. Un nègre indolente et sauvage, étranger à tout désir de progrès, d'ambition, de devoir, s'avisera-t-il jamais de remplacer cette vie imprévoyante, vagabonde et sensuelle, par les rigueurs d'un travail volontaire et d'une existence gagnée à la sueur de son front? "Cf. MERLIN, Mercédès. "Les esclaves dans les colonies espagnoles”. Em Revue des Deux Mondes, v. 27: 1841:766-767.

3 "Les philosophes et les publicistes n'ont pas, ce me semble, examiné d'assez près les questions quis tiennent à la situation des colonies européennes dans les Antilles et à l'esclavage qui s'y trouve établi. L'harmonie magique du mot liberté trompe beaucoup d'esprits et leur donne le vertige. Sans approfondir les faits qui se rattachent à ces débats, on part d'une appréciation incomplète, et, de fausse conséquence en fausse conséquence, la philantropie aboutit à faire égorger les blancs pour rendre les négres misérables, en espérant les rendre libres. Je sais qu’à ces mots les enthousiastes crieront anathème contre moi, créole endurcie, élevée dans des idées pernicieuses, et dont les intérêts se rattachent au principe de l'esclavage; mais je les laisserai dire, et m'en rapportai au bon sens des esprits droits. $\mathrm{Si}$, après avoir lu cet écrit, ils me condamnent, je me livre à eux dans mon humilité, leur demandant grace pour mon coeur en faveur de cet amour inquiet de la justice qui peut m’égarer, mais qui ne saurait jamais détruire la généreuse pitié dans le coeur d'une femme." Cf. IDEM. ibidem: 734-735.
* (Cf. RECLUS, Élisée. Les Etats-Unis et la guerre de Sécession: articles publiés dans la Revue des Deux Mondes. Paris: Ed. Soizic Alavoine-Muller, Comité des travaux historiques et scientifiques (CTHS), 2007.)

"(Cf. IDEM. "Le Brésil et la colonisation". Revue des Deux Mondes. t.39. Paris: 1 maio 1862: 930-959.)

"(IDEM. "Sentiment de la nature dans les sociétés modernes". Revue des Deux Mondes. t.63. Paris: 1866:.352.) 
Valência, pela gráfica filo-anarquista de Sempere (que, por sinal, também editou Dios y el Estado de Bakunin, com prefácio de Reclus), é Reclus também quem descreve, em chave alegórica, a floresta amazônica. A descriçãoo interessa-nos de perto e vou transcrevê-la na íntegra:

Los grandes bosques tropicales tienen otro carácter y asombran por la magnificencia, el exceso de su vegetación y la variedad de sus especies. No es un conjunto majestuoso y regular como el del bosque de abetos o alerces, sino un caos de verdor, un hacinamiento de selvas revueltas, donde la mirada trata en vano de distinguir las innumerables formas vegetales. Por encima de las anchas copas frondosas, se superponen otras copas y se yerguen las palmeras, unidas unas con otras por el inextricable lazo de las lianas: ramas rotas, suspendidas de cuerdas casi invisibles, se balancean en el espacio; brotan pándanos como cohetes verdes del enredijo de ramas y hojas de todas clases, dispuestas en forma do penachos, abanicos, ramilletes o guirnaldas; abren las orquídeas en el aire sus extrañas flores; los árboles muertos de vejez desaparecen bajo redes floridas, y la mayor parte de los troncos aun erguidos están rodeados, como con una corteza nueva, de los tallos de parásitos de elegante follaje. Mientras en los bosques del Norte se parecen todos los árboles, y sin embargo, se levantan aislados como los ciudadanos iguales en un país libre, las innumerables especies del bosque tropical, distintas unas de otras por sus dimensiones, sus formas y sus colores, parece que se confunden en la misma masa de vegetación; el árbol ha perdido su individualidad en la vida del conjunto. Una encina de la zona templada, que extiende sus ramas de rugosa corteza, hunde las raíces en el suelo resquebrajado y alfombra la tierra con sus hojas secas, siempre parece un ser independiente, hasta cuando está rodeado de otras encinas iguales, pero los árboles más hermosos de un bosque virgen de América del Sur no son así; retorcidos unos alrededor de otros, atados en todos sentidos por las lianas, medio ocultos por los parásitos que los aprietan y les beben la savia, no son más que moléculas de un inmenso organismo que cubre comarcas enteras.

El bosque tropical hay que verlo desde la superficie del mar o desde un río caudaloso, especialmente cuando la selva cubre las laderas de una colina elevada. Desde la cima hasta la base, aquélla es un océano de follaje; debajo de aquella masa movida por la brisa apenas puede columbrarse el suelo que la sostiene; parece que el bosque entero tiene su raíz en las aguas, y flota como enorme planta piramidal de 200 metros de altura. Todas las ramas están unidas entre sí y el menor estremecimiento se propaga de hoja en hoja a través de la verde inmensidad. Donde la colina presenta un declive rápido, grandes masas de follaje y flores caen de copa en copa, como los saltos de una catarata. Aquello es un Niágara de verdor. Una atmósfera húmeda y cargada de las fragancias de las plantas 
se escapa del bosque y se extiende en lontananza; en días nublados han conocido los viajeros desde el mar, a 130 kilómetros de distancia, la proximidad de las costas de Colombia por los aromas extendidos por el espacio.

De todas esas vegetaciones tropicales, tan maravillosamente ricas, la más varia es la de la cuenca del Amazonas, y bastaría para revelarlo la situación geográfica del país, porque en ninguna parte se encuentran más admirablemente unidas, en tan vasta extensión, la riqueza aluvial del terreno, la abundancia de lluvias y la actividad de los rayos solares. En un espacio de muchos millares de kilómetros de Norte a Sur y de Este a Oeste, las llanuras del Amazonas son un bosque sin límites, cortado únicamente por los anchos canales del río y de sus tributarios, los pantanos y lagunas de sus orillas y claros de hierbas altas, entre las cuales se levantan algunos árboles sueltos. Quédase atónito el botánico ante la inmensa variedad de plantas que se le presenta. Ya en el mismo río, ve las procesiones de troncos revueltos y de ramas cubiertas de hojas arrastradas por la corriente como bosque flotante; en la fangosa orilla, ve los cañaverales agrupados que avanzan como un promontorio al pie de la inmensidad verde de los árboles; después, en la misma ribera, cada tributo dejado anualmente por las aguas tiene su vegetación particular de plantas, tanto más alta, tupida y cargada por lianas cuanto más antiguo es el terreno en que crece. Más allá de esa primera muralla de árboles-muros, que tapa en muchos sitios el verdadero bosque, empieza al cabo la soledad virgen de las grandes selvas, donde la flora del Amazonas ostenta a la vez toda su delicadeza y toda su majestad, gracias al número prodigioso de plantas que la componen. Los tipos más diferentes, hierbas que se arrastran y troncos gigantescos, se mezclan y confunden. Las lianas ligeras, colgadas del ramaje, unen en la misma red todo el follaje del bosque. Cuadro maravilloso es ese, que hay que contemplar en plena naturaleza salvaje, ya a las orillas de alguna laguna en la cual se admiran las enormes hojas y las flores de la victoria, ya desde la superficie de un arroyo tortuoso, verdadero sendero líquido, festoneado de guirnaldas que se balancean por encima de la canoa de los viajeros. En ningún país del mundo se combinan la fuerza y el encanto, la grandeza del conjunto y la gracia de los pormenores de manera tan completa; aquello es el triunfo de la Naturaleza viva; el bosque es grandioso y alegre a un tiempo y nada tiene de la dulce melancolía que hay en los bosques de las zonas templadas. ${ }^{4}$

\footnotetext{
${ }^{4} \mathrm{E}$ ainda: "Si no se encuentran todas las plantas de la tierra en las inmensas selvas del Amazonas, a lo menos están representados todos los géneros por sí o por sus equivalentes. La familia de las rosáceas, que nos da los hermosos agavanzos, de los setos y las admirables rosas de nuestros jardines, que produce la mayor parte de nuestros árboles frutales. El manzano y el peral, el melocotonero, el cerezo, el almendro y otros muchos, apenas existen en los trópicos, pero los sustituye otra gran familia, la de las mirtáceas, que produce la guayaba, la pitanga y otros muchos frutos sabrosos, cuyos nombres se ignoran o se desconocen fuera
} 
- (Cf. CLARK, John P. e Martin, Camille (ed.). Anarchy, geography, modernity. The radical social thought of Élisée Reclus. Lanham: Lexington Books, 2004; Chardak, Henriette Edwige. Élisée Reclus: un encyclopediste infernal. Paris: L'Harmattan, 2005.)
O communard Reclus sentia-se poderosamente atraído pelo Brasil. Em sua obra L'Homme et la Terrre (1905-8), o geógrafo dedica o último capítulo, "Progresso", ao Brasil, citando, aliás, os pilares da biblioteca antropófaga, Jean de Léry, Claude d'Abbeville, e mesmo Montaigne. No caso de La vida en la Tierra, entretanto, Reclus parece responder ao convite à viagem baudelairiana, partindo, para retomarmos a tradução de Guilherme de Almeida, em busca de ordem, nitidez, luxo, calma e languidez. Assim sendo, encontra, na Amazônia, uma autêntica floresta de símbolos. Nesse templo hermético, tanto do ponto de vista natural quanto imaterial, ele pôde ouvir, enfim, um conjunto heteróclito de vozes confusas ("un caos de verdor, un hacinamiento de selvas revueltas"), que nada deve à rigorosa regularidade das árvores setentrionais ("un conjunto majestuoso y regular como el del bosque de abetos o alerces”).

A teoria das correspondências de Baudelaire, como sabemos, apoiava-se também num peculiar momento de êxtase, a anestesia musical de Hoffmann, graças à qual, aliás, o odor da flor maravilhosa produzia, no poeta, um efeito mágico que lhe provocava um profundo devaneio, como confessa por sinal o próprio Baudelaire, em suas Curiosidades Estéticas. Reclus, por sua vez, vale-se, da mesma forma que Baudelaire, de um antecedente livresco, o tópico opositivo norte/ sul, presente, entre outros casos, no Discurso sobre a desigualdade dos homens de Rousseau, para nos dizer que, enquanto nos bosques do Norte todas as árvores se parecem e se erguem, isoladas, "como os cidadãos iguais em um país livre", làbas, porém, nos trópicos, as inúmeras espécies da floresta, distintas unas das outras por suas dimensões, suas formas e até por suas cores, confundem-se, sem freio, na mesma massa de vegetação, por-

de las regiones tropicales. Cada zona tiene su familia especial de árboles frutales. Los humildes cereales del Norte, cuyo grano sirve de base para la alimentación del hombre, tienen como equivalente, cerca del Ecuador, la gran familia de las palmeras, muchas de cuyas especies viven a orillas del Amazonas y sus afluentes; cada río tiene su especie característica de palmera, que da a sus bosques un aspecto especial; en el río principal se suceden las variedades desde la desembocadura hasta la confluencia del Solimões con el Río Negro, y más arriba hasta las montañas del Perú. Las especies del árbol que alimenta con sus frutos a los indígenas y les da al mismo tiempo agua fresca, tejidos y materiales de construcción, son más numerosas que los cereales de loa países septentrionales. Y sin embargo, las regiones del Amazonas no se conocen más que en la vecindad inmediata de las orillas fluviales, y cada nueva exploración de los botánicos revelará la existencia de nuevos tesoros vegetales". Cf. RECLUS, Èlisée. La vida en la Tierra. Trad. Roberto Robert. Valencia, F. Sempere y Co.: (s.d.): 33-7. 
que "a árvore perdeu sua individualidade na vida de conjunto". Da biologia passamos, sem receio, à política. Tal é a cifra também da modernidade baudelairiana. Como Baudelaire, aliás, o anarquista Reclus é igualmente crítico da Revolução e, portanto, muito cético com relação ao Iluminismo, daí que, discretamente pessimista, veja uma saída no Mal, a anarquia, e não no Bem, o progresso. Logo, sua descrição da floresta tropical pode ser lida como uma reflexão em torno ao pecado original.

As Flores do Mal, como sabemos, não foi um título dado por Baudelaire. Les Lesbiennes e Limbes tinham sido cogitados por ele anteriormente. Ao que tudo indica foi Hippolyte Babou quem optou pelo título definitivo, título, aliás, que Bertold Brecht considerava errôneo porque julgava reconhecer nele uma reverência de Baudelaire à moral convencional. Sob Napoleão III, o exército já não é a flor da juventude operária - diz o estalinista Brecht, nos anos da guerra - ele é a flor da lamaceira em que vive o descamisado proletariado camponês. Nesse sentido, a massa é agora apenas uma massa de remplaçants, assim como Bonaparte é um mero remplaçant, um substituto de Napoleão e, em consequência, Baudelaire não seria mais do que um traidor a Blanqui. A derrota do anarquista - conclui Brecht - é a vitória pírrica do poeta. ${ }^{*}$ Mas, se isto é assim, é porque o autor de $A s$ Flores do Mal tinha uma visão não-dual, porém global, da modernidade, graças à qual buscava a ela pertencer, muito embora, criticando-a. A idéia, como sabemos, remete-nos à noção de pecado original. Ela se mostra de várias formas.

Baudelaire compara, por exemplo, em seus poemas, a cabeleira feminina a vários continentes, a uma Ásia langorosa e a uma África escaldante. Com essa imagem ele acompanhava, entre outros, o testemunho acima citado da condessa de Merlin. Mas observe-se que, nas antípodas do poeta, o geógrafo Reclus, conservando-a, modula, porém, a equação. A floresta tropical é trescalante, tal como a cabeleira na alcova dos amantes; ela é pecado, sim, mas porque ela é vida, ela é um Niágara de infinitos verdes, "uma atmosfera úmida e carregada das fragrâncias das plantas [que] escapa do bosque e se espalha ao longe". Como leremos mais adiante em Proust, em seu elogio da dispersão do jato d'água, a modernidade é, simplesmente, uma viagem à procura de objeto. A modernidade está atravessada por uma hiância, por um vazio que lhe é inerente. Por isso mesmo, Reclus não hesita em chamar essa cena, tal como Humboldt ou, ainda, o próprio Baudelaire, de "quadro ma-
* (BRECHT, Bertold. "La belleza de las poesias de Baudelaire" . Em: El compromiso en literatura y arte. Ed. W. Hecht. Trad. J. Fontcuberta. $2^{a}$ ed. Barcelona, Península: 1984:306-7) 
- (Cf. STIERLE, Karheinz. "Baudelaire and the Tradition of the Tableau de Paris". New Literary History, vol. XI, $\mathrm{n}^{\circ} 2$ : winter 1980: 345-361.)

ravilhoso", $5^{*}$ porque é no mais distante, isto é, na Amazônia, com efeito, onde se combinam, de maneira absolutamente completa, valores antagônicos como a força e o encanto, a grandeza do conjunto e a graça dos pormenores. ${ }^{6}$ Aquilo, a seu ver, é o triunfo da Natureza viva, de uma natureza pós-natural ou mesmo anti-moderna, porque a floresta é, ao mesmo tempo, grandiosa e alegre, já que alheia por completo à doce e apática melancolia dos bosques temperados. A Amazônia é, em suma, a alteridade radical do moderno: potência e deiscência são nela inseparáveis.

Essa indecidibilidade entre atividade e passividade é, precisamente, um dos traços decisivos da modernidade de Baudelaire. Enquanto a euforia histórica do progressismo conduz a sociedade ao egoísmo e à preguiça, o pessimismo, uma forma de ceticismo moral, estimula, no poeta, a renovação ético-estética pela via da convicção de que a moral é antinatural. A civilização não é sinônimo de progresso material, nos diz Baudelaire em Meu coração desnudado, mas um mero equivalente da rasura ou obliteração das marcas do pecado original. Aliás, Murilo Mendes, aplicado leitor de Joseph de Maistre, guia de Baudelaire nesse ponto, compreendeu-o corretamente. Às vésperas do Estado Novo escreve, contrariamente à leitura de Breton, que

Baudelaire é um poeta informado do catolicismo até a medula. Admito que não fosse pontual ao culto, mesmo porque viveu numa época agitadíssima e de grande decadência religiosa. $\mathrm{O}$ espetáculo do clero de mãos dadas com governos violentos e reacionários deveria esfriar bastante um espírito sincero e independente. Mas um homem que cultivava em alto grau idéias profundamente católicas, que tinha um conceito gravíssimo de pecado, de julgamento e de inferno como o iluminado Les Fleurs du Mal, desautoriza pela sua obra a opinião de Breton. Baudelaire é um dos raríssimos homens que, a propósito da crítica de pintura e música, falam do pecado original. E não uma vez, mas muitas (vide "L'Art Romantique" e "Curiosités esthétiques"). No seu livro Mon coeur mis à nu - livro que transpira catolicismo em todas as páginas - declara que "a verdadeira civilização não consiste no gás, nem na máquina a vapor, nem nas me-

\footnotetext{
${ }^{5}$ A solução dos quadros urbanos, em Baudelaire, nada mais é do que uma retomada da tradição dos tableaux de Paris. Cf. STIERLE, Karheinz. "Baudelaire and the Tradition of the Tableau de Paris". New Literary History, vol. XI, no 2: winter 1980: 345-361.

${ }^{6}$ A partir, entre outros casos, das anotações de William James, na Amazônia, a historiadora Nancy Leys Stepan analiza de que modo a natureza tropical funciona como laboratório de transformações raciais e culturais em seu livro Picturing Tropical Nature (Ithaca: Cornell University Press, 2001).
} 
sas giratórias do espiritismo - e sim na diminuição dos vestígios do pecado original'. A meu ver só um teólogo, um homem inspirado pelo Espírito Santo, poderia ter escrito uma tal frase.

Lúcio Cardoso também soube destacar, em Baudelaire, um peculiar lastro do catolicismo, o desespero, que ele interpretava à luz de Max Scheler. Ora, é por esta posição metapolítica, como admite o próprio poeta em "Héautontimorouménos", que para Baudelaire se equiparam a ferida e o punhal, o rosto e a bofetada, a roda e a carne lacerada, o carrasco e a vítima, afinal. Mas vítima e carrasco, assim nivelados, não estão só em Baudelaire. Eles estão em $O$ mundo como vontade e representação, onde Schopenhauer estipula que ambos perfazem a unidade. Estão em Emerson, para quem "every creature is man agent or patient". Estão em Caillois e sua "Sociologia do carrasco", proclamada, em certo sentido, contra Borges, ${ }^{8}$ ou seja, compartilhada, até certo ponto, com Borges. Estão em Bataille e sua parte maldita; estão em Klossowski, unindo, na esteira de $A$ idade de ouro de Buñuel, Sade e Revolução; estão em Lacan e seu objeto a minúsculo, o objeto causa do desejo, esse objeto informe que em si articula Kant e Sade; estão em Jean-Luc Nancy e sua comunidade inoperante, e estão, enfim, em Blanchot e o diálogo infinito de uma comunidade inconfessável.

\footnotetext{
${ }^{7}$ Impugnando a leitura laicista de Breton, Murilo Mendes pondera que a questão se resume no desconhecimento do catolicismo por parte de Breton. "Ele julga que essa doutrina só pode abrigar os bem-pensantes, os carolas, os conformados com a mediocridade e os fanáticos da ordem policial. Engano puro. Pretendo mesmo que o catolicismo seja mais revolucionário e explosivo que o próprio marxismo. Enquanto o marxismo espera a destruição de uma classe - a capitalista - e a instalação de um confortável paraíso na terra - o otimismo de adolescente!... - o catolicismo espera a destruição do universo inteiro. Não ficará pedra sobre pedra..." Diz ainda que Breton é católico sem saber. "No mesmíssimo livro Position politique du surrealisme, ele afirma que o artista deve buscar suas inspiraçóes no tesouro coletivo, na alma popular devido à solidariedade que liga os homens entre si. Ao escrever isto, transcreveu um dos princípios básicos do grande dogma da Comunhão dos santos...". Cf. MENDES, Murilo. "Breton, Rimbaud e Baudelaire". Em: Dom Casmurro. ano 1, n¹6. Rio de Janeiro: 26 ago. 1937: 2.

${ }^{8}$ Caillois, um dos que aceita o convite à viagem, publica sua primeira colaboração em Sur, justamente "Sociologia do carrasco", junto com o manifesto do Colégio de Sociologia, assinado por Bataille, Leiris e o próprio Caillois, como coisa só dele, cosa nostra, logo em frente da primeira colaboração narrativa de Borges na mesma revista, "Pierre Menard, autor do Quixote". Ao republicar o conto em livro, Borges introduzou nele uma série de modificaçóes, entre as quais, a data e local do conto, "Nîmes, 1939", cidade onde, por sinal, nasceu e viveu o último carrasco francês. Toda uma teoria da soberania se arma, sibilinamente, nas entrelinhas desse proto-texto. Cf. ANTELO, Raul. "Notas performativas sobre el delito verbal”. Variaciones Borges. no 2, Aarhus (Dinamarca): 1996.
}

* (Cf. CARDOSO, Lúcio. "Baudelaire" Em Autores e Livros. Suplemento Literário de A Manhã. Rio de Janeiro: 13 fev. 1944: 94-5.) 
Por tudo isso, em função dessa reversibilidade entre o agente e o paciente, não há como ler os poemas de As Flores do Mal, sem neles ler a cultura que os torna possíveis. Ambos se exibem na mesma vitrine: a Revue des Deux Mondes. Aliás, a epígrafe dessa primeira versão, uma citação de Théodore Agrippa d'Aubigné, tirada de As trágicas, é bem eloqüente.

On dit qu'il faut couler les exécrables choses

Dans le puits de l'oubli et au sépulchre encloses,

Et que par les écrits le mal ressuscité

Infectera les moeurs de la postérité;

Mais le vice n'a point pour mère la science,

Et la vertu n'est pas fille de l'ignorance.

Contudo, não há também como esconder que o editor dessa primeiríssima edição das Flores do Mal, em 1855, provavelmente Émile Montégut, sentiu-se na obrigação de ponderar que a $R e$ vue acolhia os poemas de Baudelaire só por uma sintonia pluralista com o presente:

En publiant les vers qu'on va lire, nous croyons montrer une fois de plus combien l'esprit qui nous anime est favorable aux essais, aux tentatives dans les sens les plus divers. Ce qui nous paraît ici mériter l'intérèt, c'est l'expression vive et curieuse même dans sa violence de quelques défaillances, de quelques douleurs morales que, sans les partager ni les discuter, on doit tenir à connaître comme un des signes de notre temps. Il nous semble d'ailleurs qu'il est des cas où la publicité n'est pas seulement un encouragement, où elle peut avoir l'influence d'un conseil utile, et appeler le vrai talent à se dégager, à se fortifier, en élargissant ses voies, en étendant son horizon.

Da parte de Baudelaire, porém, não surpreende que ele tenha escolhido a Revue para publicar dezoito peças de seu livro, ${ }^{9}$ porque sendo des Deux Mondes, ela é veículo dessa expansão ultramarina tida, unanimemente, como moderna e, em consequência, considerada compensatória já que o mar, o mar vazio, "nos consola os labores". Não em vão, o jornal literário Le Hibou Philosophe,

\footnotetext{
${ }^{9}$ São elas: I. Au lecteur; II. Réversibilité; III. Le tonneau de la haine; IV. La confession; V. L’aure spirituelle; VI. La volupté; VII. Voyage a Cythère; VIII. A la belle aux cheveux d'or; IX. L'invitation au voyage; X. Moesta et errabunda; XI. La cloche; XII. L'ennemi; XIII. La vie antérieure; XIV. Le spleen; XV. Remords posthume; XVI. Le guignon; XVII. La Beatrice; XVIII. L'amour et le crane (D'après une vieille gravure). Cf. Baudelaire, Charles."Les Fleurs du mal". Revue des Deux Mondes. a. 25, v. 10. Paris: 1855: 1079-1093.
} 
de cuja redação fazia parte o próprio Baudelaire, chegou a planejar uma análise da direção e das tendências da Revue des Deux Mondes. ${ }^{*}$ A tal ponto, considerava sintomática essa revista que, dirigida por Ferdinand Brunetière, seria, ela própria, um epítome da III República das Letras.

Ativo e passivo, ao mesmo tempo, na circulação entre dois mundos, o mar, que transportava a revista, é dotado, como diz o poeta, da "sublime função do materno acalanto". Ora, o que entendia Baudelaire por sublime? Certamente a Revolução. Mas não exatamente a Revolução como ruptura, porém, como retorno ou revulsão. Burke, na sua Indagação filosófica sobre a origem de nossas idéias acerca do sublime e do belo, definira o sublime como algo próximo do terror, mas Kant, pelo contrário, homologava o sublime ao ilimitado. Enquanto o belo era associado a alguma forma finita, o sublime podia ser de dois tipos, matemático, ou seja, aquilo que é imensamente grande, ou dinâmico, aquilo que possui uma potência assustadora. $\mathrm{O}$ mar, essa matéria onde o homem mergulha na própria imagem ("O homem e o mar"), esse mar, pois, que vincula ao separar e distancia ao associar os Dois Mundos é, simultaneamente, matemático e dinâmico. $\mathrm{O}$ mar de Baudelaire é um instrumento do colonialismo, que nos leva ao paraíso ("Lá tudo é belo e se ordena / - luxo volúpia serena”, promete, de fato, o "Convite à viagem"), mas esse imenso paraíso de prazeres furtivos "mais longe deve estar do que a Índia e a China" ("Moesta et errabunda"), razão pela qual nunca, a rigor, o veremos: só podemos evocá-lo através de gritos pungitivos. Não belos, porém, sublimes, já que dotados de uma limitada função compensatória, a de "materno acalanto". ${ }^{10}$

${ }^{10}$ Théophile Gautier recusa a idéia de que o sublime baudelairiano fosse produto de seu consumo de excitantes. "Baudelaire era sóbrio como todos os trabalhadores e, admitindo muito embora que o gosto de criar para si um paraíso artificial por meio de um excitante qualquer, ópio, haxixe, vinho, álcool ou tabaco, parece pertencer á própria natureza do homem pois que se pode encontrá-lo em todas as épocas, em todos os países, nas barbáries como nas civilizações e até no estado selvagem, ele via nisso uma prova da perversidade original, uma tentativa ímpia de escapar à dor necessária, uma pura sugestão satânica para usurpar, desde já, a felicidade reservada mais tarde como recompensa à resignação, à vontade, à virtude, ao esforço persistente para o bem e o belo. Ele pensava que o diabo dizia aos comedores de haxixe e aos bebedores de ópio, como outrora a nossos primeiros pais: 'Se provardes deste fruto, sereis como deuses', e que não cumpria a palavra como não cumpriu com Adão e Eva; pois, no dia seguinte, o deus, enfraquecido, enervado, desceu abaixo do bicho e permanece isolado num vazio imenso, não tendo outro recurso para escapar de si mesmo que não seja recorrer

(BAUDELAIRE, C. "[Notes pour la rédaction et la composition du journal] Le $\mathrm{Hi}$ bou Philosophe" . Em: Oeuvres Complètes. Ed. Y. G. Le Dantec e C. Pichois. Paris, Gallimard:1961: 629.)

" (Cf. RECLUS, Elisée. "L'Océan. Étude de Physique Maritime". Revue des Deux Mondes. a.37, v. 52. Paris: jul 1867:.963-993.)

(Cf. Miller, Christopher L. "Orientalisme, colonialisme". Em: Hollier, Denis (ed.). De la littérature française. Paris, Bordas: 1993: 658-664.) 
(Cf. JAMESON, Frederic. "Baudelaire as Modernist and Postmodernist: The Dissolution of the Referent and the Artificial Sublime". Em HOSEK, Chaviva \& PARKER, Patricia (ed.). Lyric Poetry: Beyond New Criticism. Ithaca: Cornell University Press: 1985: 247-263.)

(COMPAGNON, Antoine. Baudelaire devant l'innombrable. Paris: Seuil: 2003.)

(IDEM. Los antimodernos. Trad. Manuel Arranz. Barcelona: Acantilado, 2007.)
Fredric Jameson mostrou-nos, oportunamente, a dupla condição de Baudelaire, tão moderno quanto pós-moderno, ${ }^{*}$ algo, a seu modo, adiantado, oportunamente, por Dante Milano ${ }^{11}$ ou Julio Cortázar. ${ }^{12}$ Antoine Compagnon, por sua vez, reconstruiu o conflito de valores suscitado por sua poesia, através de uma série de interpretaçôes em torno ao escritor ${ }^{*}$ que, em seu último livro, cristalizam-lhe o qualificativo de antimoderno. Baudelaire é antimoderno porque é um moderno arrastado pela corrente histórica, permanecendo incapaz, contudo, de lamentar o passado. $\mathrm{O}$ antimoderno - diz Compagnon - é o moderno em liberdade para questionar a própria modernidade e essa disponibilidade crítica se exprime através de quatro figuras ou argumentos: o argumento político (o antimoderno é crítico da Revolução), o filosófico (o antimoderno é cético diante do Iluminismo), o ético (o antimoderno é culturalmente pessimista e adere ao Mal); daí que o último argumento seja propriamente teológico (o antimoderno não cessa de se reportar ao pecado original).

ao seu veneno, cuja dose deve aumentar gradualmente. Que haja experimentado haxixe uma ou duas vezes como experiência fisiológica, é possível e até provável, mas não fez da droga um uso contínuo. Essa felicidade comprada na farmácia, e que se carrega no bolso do colete, repugnava-lhe, aliás, e ele comparava o êxtase que produz à de um maníaco para quem telas pintadas e cenários grotescos substituiriam verdadeiros móveis e jardins perfumados de flores reais”. Gautier diz, além do mais, que Baudelaire raramente foi, e por sinal como simples observador, às sessōes do Hotel Pimodan, onde o grupo dele, integrado, entre outros, por Balzac, se reunia para tomar dawamesk, tal como o próprio Gautier narra, justamente,em artigo para a Revue des Deux Mondes, "Le Club des haschischins" [O clube dos haxixeiros]."Depois de umas dez experiências - confessa Gautier - renunciamos para sempre a essa droga inebriante, não que ela nos tivesse feito mal fisicamente, mas o verdadeiro literato precisa apenas de seus sonhos naturais, e não gosta que o seu pensamento receba a influência de um agente qualquer”. Cf GAUTIER, Theophile. Baudelaire. Trad. Mário Laranjeira. Apresentação Glória Amaral. São Paulo: Boitempo, 2004: 74-75.

${ }^{11}$ Milano admirava, em Baudelaire, o poeta puro, dono de "uma justeza de pensamento e de forma incomparáveis, uma unidade espiritual, uma severidade autocrítica, um gosto e segurança em suas opiniōes de crítico de arte, uma linha de conduta poética impecável”. Cf. MILANO, Dante. “Sobre Baudelaire”. Em: Autores e Livros. Suplemento Literário de A Manhã. Rio de Janeiro: 14 dez. 1941: 399.

12 "Baudelaire pone las armas en las manos de quienes (pensando desde la enrarecida perspectiva de Mallarmé y su descendencia) denuncian la impureza de su obra; porque es él quien descubre de una vez para siempre la esencialidad incontaminable de la poesía; es él quien aprehende su misterio en el acto mismo de la formulación verbal; y si la ganga personal y circunstante le veda replicar exactamente a su intuición con su obra, es él quien nos alcanza, desde Les Fleurs du Mal, una poesía ya a salvo de todo malentendido futuro, de toda confusión con la estética o la ética." Cf. CORTÁZAR, Julio. "François Porché - Baudelaire. Historia de un alma”. Em Sur. a.17, no 176, Buenos Aires: jun.1949:71. 
Ora, como sintomas desse antimodernismo de Baudelaire, as Flores do Mal nos fornecem imagens políticas, éticas, filosóficas e até mesmo teológicas inerentes à própria modernidade ocidental. "L'une des grandes forces de l'image - nos diz Didi-Huberman em "L'image brûle" - est de faire en même temps symptôme (interruption dans le savoir) et connaissance (interruption dans le chaos)".* Conseguir ler tais imagens é detectar, portanto, onde elas ardem, onde queimam, onde se consomem. Como sintoma, nas páginas da Revue des Deux Mondes, os poemas de Baudelaire lêem-se, em rede, com os textos de Elisée Reclus, de Ferrari, de Adolphe d'Assier, 'de Théodore Lacordaire* ou Émile Adet ${ }^{*}$. São textos, como os de Charles de Mazade, sobre a violência política, filosófica e moral retratada no Facundo, ${ }^{*}$ que, junto aos da condessa de Merlin, de extração ética, nos fornecem imagens do exotismo do Mal; algo que também constatamos, tanto nas resenhas proto-heterológicas da antiga vida mexicana de Ferdinand Denis, ${ }^{*}$ como nos poemas dedicados à Espanha, de Théophile Gautier, a quem são dedicadas as Flores do Mal, poemas esses de Gautier em aberta sintonia com a modernidade "oriental" de Manet, esse discípulo de Goya ou Velázquez. A literatura e o mal, o livro de Georges Bataille, começa a se escrever nessas páginas de Deux Mondes. E além de os lermos em rede, como sintoma, é preciso lê-los também como peculiares exercícios de saber ou conhecimento. No dizer cauteloso da própria Revue, como "l'expression vive et curieuse même dans sa violence de quelques défaillances, de quelques douleurs morales que, sans le partager ni les discuter" - ou seja, com uma certa distância aristocrática, levemente apática - "on doit tenir à connaître comme un des signes de notre temps".
"(DIDI-HUBERMAN, Georges. "L'image brûle". Em ZIMMERMANN, Laurent (ed.). Penser par les images. Autour des travaux de Georges Didi-Huberman. Nantes: Cécile Defaut: 2006: 11-52.)

•(FERRARI. "Des idées de I'École de Fourier depuis 1850". Em Revue des Deux Mondes. a. 14, v.11.Paris: 1845: 389-434.)

"(D'ASSIER, Adolphe. "L'Eldorado Brésilien". Em Revue des Deux Mondes. vol. 52, Paris:15 jul. 1864: 323-358.)

"(LACORDAIRE, Théodore. "Excursion dans l'Oyapock". Em Revue des Deux Mondes. Paris: 15 dez. 1832.)

"(ADET, Émile. "L'Empire du Brésil et la société bresilienne en 1850". Em Revue des Deux Mondes. Paris, a.21, v.9.Paris: 1851: 1082-1405 e v. 10: 1028-1048.)

"(MAZADE, Charles de. "De I'Americanisme et des Republiques du Sud". Em Revue des Deux Mondes, a. 16, v. 16. Paris: 1846:.625-659.)

" (DENIS, Ferdinand. "Antiquités du Mexique". Em Revue des Deux Mondes. a.3, v. 1. Paris: 1831: 74-104.)

* (GAutier, Théophile. "Espagne". Em Revue des Deux Mondes. v. 27, Paris: $1841: .969-976$ e v. 28 : 1841: 659-664.) 


\section{Raúl Antelo}

Raúl Antelo é professor titular de literatura brasileira na Universidade Federal de Santa Catarina. Pesquisador do CNPq, foi Guggenheim Fellow e professor visitante em Universidades americanas e européias. É autor de vários livros, dentre eles, Algaravia. Discursos de nação, Transgressão \& Modernidade, Potências da imagem e Maria con Marcel. Duchamp en los trópicos. Colaborou em várias obras coletivas, como Nenhum Brasil existe:Pequena Enciclopédia; Literary Cultures of Latin America. A Comparative History, The Future of Cultural Studies; Cánones literarios masculinos y relecturas transculturales; Sujetos en tránsito; Reescrituras e Sobre Augusto de Campos. Como editor, é responsável pelo último número de Review (Routledge, 2007) bem como por $A$ alma encantadora das ruas de João do Rio; Ronda das Américas de Jorge Amado; Antonio Candido y los estudios latinoamericanos, e a Obra Completa de Oliverio Girondo para a coleção Archives da Unesco.

Palavras-chave: Baudelaire; Imagens; modernidade transatlântica

\section{Resumo}

Uma das forças da imagem é a de constituir ao mesmo tempo sintoma e conhecimento. As Flores do Mal, uma série de quadros, isto é, de imagens, publicado pela primeira vez na Revue des Deux Mondes, oferece-nos uma imagem antimoderna e transatlântica das idéias de Baudelaire.

\section{Abstract}

Key words: Baudelaire; Images; transatlantic modernity Mots-clés: Baudelaire; Images; modernité transatlantique
One of the main forces of images is to be simultaneously a sympthom and a kind of knowledge. The Flowers of Evil, a series of tableaux, i.e. of images, published for the first time at Revue des Deux Mondes, bring us an image of anti-modern and transatlantic ideas by Baudelaire.

\section{Resumé}

L'une des forces de l'image est de faire en même temps symptôme et connaissance. Les Fleus du Mal, une série de tableaux, c'est à dire, d'images, publié par la première fois dans la Revue des Deux Mondes, nous offre une image anti-moderne et trans-atlantique des idées de Baudelaire. 